\title{
Marie Desplechin: Moj rođak Gérard / s francuskog prevela Ivana Ramić
}

Kako sam otkrila da sam zločesta, ja koja sam puka dobrota? Mogu vam ispričati. To je zapisano u vremenu. Da muškarci izlaze iz sobe. Oni iz obitelji mogu ostati. Toliko volim kad pokazuju suosjećanje.

Željela sam otići, moj život s mužem bio je potrošen. Nema sumnje da sam mogla još malo ostati, ali srce mi je bilo drugdje. Ne nužno uvijek na istom mjestu, ja sam blizu ljubavi. No u svakom slučaju, više nije bilo u mojoj kuhinji. Ni srce moga muža nije osobito bilo u kući. No ipak, on je muškarac, a oni nemaju isti pogled na svijet. Volim te, volim te, još bi ponekad ponovio iz puke potrebe, kada bi vidio da namjeravam otići. Nije da mu više nisam vjerovala, ali nisam imala što tamo raditi. Smijala sam se.

Nakon svih tih događaja koji su se, čini se, brzo odvijali, ali mi oduzeli više godina života, napustila sam zajednički dom. Našla sam utočište kod svog rođaka Gérarda. Sve se samo posložilo. Moj brat, koji je kod Gérarda stanovao tri-četiri godine ili više, odlučio je živjeti sam, u vlastitom stanu. Ta ga mogućnost nije činila ništa sretnijim, ali je mislio da će mu promijeniti život.

Našao je dakle novi stan, na šestome katu, s gredama na stropu. Tog poslijepodneva kada je otišao, stavila sam karte na stol. Jednostavno sam pitala Gérarda, koji se bojao samoće, mogu li stanovati kod njega. Sljedećeg ponedjeljka spakirala sam kofere, obavijestila djecu o novonastalim promjenama i uselila se u slobodnu sobicu.

U toj sam sobi živjela osam mjeseci prije nego što sam najurila muža i vratila se svojoj dječici. Zašto toliko dugo? To se i sama ponekad pitam. Naravno, zato što mi je Gérard bio drag, jer sam žudjela za slobodom, ali i zato što sam se osjećala kao grešnica koja je odjednom razorila vlastitu obitelj kao kulu od karata, usprkos izgovorenim volim te, volim te moga muža. 
Ovdje, kod Gérarda, shvatila sam da su osjećaji mač s dvije oštrice od kojih sam osjetila obje, muku i mir.

"Dobar ti dan", rekao bi mi svake večeri, kao da me prvi put tamo vidi, u kuhinji ili u laštenju parketa. A kada se kasno vraćao, ja bih pokušavala zaspati čekajući ga u svom krevetu, sa širom otvorenim vratima. On je čekao posao pomalo gubeći glavu. Često bi izlazio ujutro i vraćao se kasno navečer. Nalijevao se velikim količinama alkohola. Nisam mu imala na čemu zavidjeti, i sama sam mnogo pila, što zbog umora, što zbog muke što sam odvojena od djece i što moram zarađivati za oboje.

To što znam zarađivati novac moja je mana. Ne toliko da mogu graditi vile na Azurnoj obali, ali dovoljno za vođenje kućanstva. Napuštajući tada svoj dom, uvjerila sam sve oko sebe da se ne moraju brinuti jer ću se ja za sve pobrinuti. I evo me kako nerazborito plaćam troškove stanova. Moj je muž to dozvolio, ne iz loših namjera, nego da olakša situaciju. Nikada se u životu nisam toliko naplaćala.

Ponekad smo Gérard i ja gledali televiziju, izvaljeni na mom krevetu, jedući tjesteninu iz njegovih velikih tanjura i ispijajući na litre smeđeg piva. Nekada bi nam došlo da pozovemo prijatelje ispred našeg malog kamina. Na vatri bismo pekli ogromne krumpire i jeli ih s vrhnjem.

Nakon toga bismo zaspali uz glazbu. Ponekad zato da lakše utonemo u san. A ponekad da prekrijemo buku kreveta kada bi on ili ja nekoga doveli. Bili smo diskretni jedan prema drugome. Također smo pazili na to da se nijedno od nas ne osjeća previše usamljeno u drugoj sobi. U našoj zajedničkoj dnevnoj sobi gramofon i linija bili su pupak stana i svjedoci naše stidljivosti.

U našim sjećanjima tih nekoliko mjeseci nije bilo dobro razdoblje za ljubav. Gérard, koji je već deset godina trčao za istom djevojkom, visokom Šveđankom koja je bila istodobno rezervirana i zanesenjakinja, posezao je za utjehu za drugim djevojkama. Ja se pak nisam uspijevala otkačiti od momka koji mi je ukrao srce prije više od godine dana. Na samom sam ga početku, kao i obično, ismijavala kao i druge. Zgrabila sam ga tamo gdje sam ga našla, povlačeći se u društvu svoje braće i rođaka. Muškarci su uistinu poput zumbula, uberemo ih na svom putu, sve ovisi o itinerarima. No potrebno se čuvati dobro poznatih putova, jer ako započinjemo ljubavne veze u 
bratskom okruženju, riskiramo miješanje i bliskost. Ali ja o tome još nisam razmišljala. Blesava kao i prije, nisam predvidjela koliko će potrajati.

Baš kad sam ga počela gledati drugim očima, puna osjećaja i žaljenja, on je dignuo sidro. Ali ovakvu će vam priču ispričati bilo koja djevojka koju upitate na ulici, uredu ili ako više volite, na plesu.

Istina je da je otišao, da se vratio, da je ponovno otišao, ponovno se vratio i tako u nedogled. Toliko me vrtio oko malog prsta da sam na kraju provodila vrijeme čekajući ga. Nije da nisam pokušavala naći druge ljubavnike. Nisam baš lakoumna. Ali s prvim nisam uspijevala završiti priču. S drugim sam se dosađivala u restoranu, dosađivala sam se na telefonu, dosađivala sam se čak i u krevetu, u samoj srži stvari. Uzaludno je bilo glumiti princezu, bila sam obuzeta, potpuno obuzeta.

"Mlađa sestra mog prijatelja Didiera stanovat će kod mene", rekao mi je jednoga dana u svojoj kuhinji, dok sam promatrala njegovo rublje koje je visilo iznad sudopera.

"A da", odgovorila sam, uzimajući čašu piva i cigaretu.

"Obitelj joj nema novca, radim im uslugu".

U jednu ili drugu ruku, on je tip koji voli raditi usluge, dovoljno da vam je u očima malo osjećaja ili žaljenja.

"Je li zgodna?" upitala sam ga.

Ali ne zavaravam se, nemam više te godine.

"Cura svježa i potpuno zdrava", odgovorio mi je, misleći time da se radi o nedostacima mladosti, grdno se prevarivši.

Smijao se kao da posjeduje dvije stotine godina mudrosti, a ja još ne vjerujem da bi se ijedan muškarac umirio pored mlade cure za dvije stotine kukavnih godina. Smijehom mi je htio pokazati udaljenost između njega i male, i drukčiju vrstu pažnje zbog mog položaja.

Otkad znam za sebe, prepoznajem takav smijeh. To je otrcana stara pjesma koju sam već čula. Govori mi da će mala biti u njegovu krevetu prije nego se okrenem. Ne zamjeram to mladim 
curama, nije u tome stvar. Ne zamjeram ni muškarcima, oni ne znaju što im se događa. Kako nema koristi od sprečavanja, ništa nisam rekla.

Petnaest dana nakon toga mala je bila u njegovu krevetu. Računajte šesnaest dana i već su bili u javnosti ruku pod ruku. To je bilo prvi put da me uistinu napustio. Promijenila sam posao, dosađivala se. Ne želim isticati brigu koju mi je tada zadao. Uvijek, kao i svi drugi, vjerujem da se umire od ljubavi, ali na kraju ipak ne umrem.

Lijepa mala, plava i zaobljena, s velikim grudima. Kad mu je dala nogu i ostavila ga, vratio se na vrhovima prstiju, ali što sam mogla. Moj krevet nije tako tijesan, primila sam ga nazad. Bilo je to prvi put, ali ne i posljednji.

“Gotovo je, gotovo”, rekao mi je.

No ona se zbog toga nije iselila iz stana, zbog novčanih je problema ostala promatrati defile i, silom prilika, mene. Nisam rekla ništa, nisam željela pustiti da itko završi na ulici ni da obitelji budu u oskudici.

Jedne me večeri pozvao k sebi i smjestila sam se u kuhinji, na svoje staro mjesto pored rublja, uz pivo. Kad evo, otvaraju se vrata, a mala želi pozdraviti velike. Pomalja nos potpuno prirodno.

“Evo, upoznajte se”, rekao je.

On nas upoznaje.

"Dobra večer", rekla sam rezervirano, gnječeći cigaretu u pepeljari.

Ali riječ me presjekla. Pristojno čekam da mala zatvori za sobom vrata, ona je mlađa. Ustajem, uzimam kaput i izlazim bez pozdrava.

Te je večeri ostao potpuno sam sa svojom malom i mojim pivom. Čemu služi to što imam intuiciju, ponekad se pitam.

Sjela sam u metro, s rukama u džepovima. Vratila sam se Gérardu.

"O draga moja", rekao je Gérard grleći me kad sam neočekivamo došla, "kakva pustolovina od života. “ 
Odveo me u našu zajedničku dnevnu sobu. U njoj su ostali mladići, među njima i moja braća, zajedno večerali za našim stolom. Promatrala sam skup s određenim zadovoljstvom. Svi ti veliki dečki u mom okruženju, to mi više ne treba, rekla sam samoj sebi. Ne mrzim žene, može se reći da imam dobar odnos s njima. Ali cijenim društvo muškaraca i njihovo svakidašnje prisustvo, mislili o tome što god htjeli.

Sjedeći za stolom, ispričala sam im svoju noćnu neugodnost dok je Gérard oprao tanjur za mene, pod mlazom vode. Slušali su me bez komentara, jer malu su vidjeli, s obzirom na to da su se ovi muškarci poznavali, kao prijatelji ili kolege koji su dugo radili u istoj kategoriji poslova. Blago su se smiješili, a ja sam mislila da se svaki od njih sjetio slične priče.

Malo kasnije zazvonio je telefon, za mene.

"Zašto si samo tako otišla?" upitao je glas s druge strane žice.

Kako da mu kažem. Željela sam spavati potpuno sama.

Svakog sam jutra ustajala prije zore, srećom bila je zima. Izašla bih zaraditi novac za telefon, selidbu i zbog različitih kontakata. Navečer, ponekad ujutro, otišla bih vidjeti djecu, kojima su oči uvijek bile na rubu suza kada bih izlazila iz stana. Nakon toga bih se vratila u svoju sobu, kod Gérarda, noseći svoje torbe u metro, uza sve to dosta umorna, i tužna kako to žena bez djece može biti. Ne ljutim se na njihovog oca, osim toga, kao što kaže moja majka, ja sam ta koja je otišla. Muškarci nemaju isti osjećaj obveze. No ne gunđajmo, sad je gotovo, i ostaje samo uspomena.

Jedne se večeri vratim u naš stančić. Pojedem nešto tjestenine s Gérardom i operem suđe. Nakon toga krenem čitati u svom krevetu potpuno sama. Nisam srce našla na cesti, onaj na kojeg mislim ne razbija glavu oko toga da me nazove. Pogledajmo istini u oči. Kako je govorila moja mama, tražim ih, nađem ih, ne vraćajmo se na tu temu.

Telefon zazvoni kad sam već izgubila strpljenje.

"Za ime Božje", čujem glas s druge strane žice prije nego što sam uspjela izgovoriti Halo!

"No dobro", izgovorim, "što se dogodilo?"

Moja je narav znatiželjna i majčinska, navikla sam na jadikovke. 
"Počinila je samoubojstvo", kaže mi. "Pokušavam doći do Didiera da ga obavijestim, ne uspijevam."

Srce mi se počinje pržiti. Samoubojstvo je dakako velika stvar. Imala sam nekoliko bliskih osoba koje su to učinile, od kojih mi je jedna slomila srce. Ali bila sam mlađa, a radilo se o muškarcu. Ovdje govorim o samoubojstvima nakon kojih je slijedila okrutna smrt, u tom slučaju pucnjem iz puške u usta. Ali ne želim spominjati užas. Jer, jednako tako sam znala za hrpu samoubojstava mladih djevojaka, s tabletama za spavanje i ispumpavanjem želuca, sve to da bi završile u bolnici na hrapavoj posteljini i primale direktno sažaljenje. U ovom trenutku vlastite povijesti ipak mislim na najgore, ne uspijevam postupiti drugačije, ja sam othranjena na mlijeku drame.

"Je li mrtva?" pitam kao iz vedra neba.

Ne, na sreću, nije mrtva. Evo me kako postavljam pitanja o samoubojstvu kao da je mala neki hrčak kojeg loše hrane, a ne okrugla plavuša koja se meškolji pod tijelom čovjeka kojeg volim.

"Brine li se itko o njoj?"

"Je li bila dobar student?"

"Je li imala prijatelja?"

Napokon pitam mogu li za nju učiniti što diskretno, jer ako joj namjeravam pomoći, ne želim da to bude posjećivanje. U svemu tome ne mislim na osobu, nego na situaciju.

Ipak volim djelovati pod krinkom nemara. Divim se efikasnosti, često primijeti moja mama kada joj pospremam kuhinju. No istina je banalnija: sve dok se nešto događa, ne razmišljam, brige mi izmiču. Dok telefoniram, komešam se poput grupe časnih sestara na indijskom otpadu. Na sreću, u toj priči ne mogu ništa dobro učiniti, hvala Bogu, na što bih sličila, pitam se.

Evo priče o samoubojstvu koja završava, mala odnosi svu svoju ljupkost u bolnicu kako bi maštala o životu po svojoj volji, a onaj drugi poklapa slušalicu sav zaokupljen kako će sve poznate obavijestiti, njoj u korist. Samoubojstvo mlade djevojke događaj je vrijedan toga da bude vijest. Zbrojite dva i dva, opet sam ja ta koja se nalazi sama u krevetu, budna kao da je jutro, obaviještena o tome potpuno beskorisno. Izlazim iz kreveta kako bih razglasila vijest, obuvam svoje debele čarape, prolazim kroz našu zajedničku dnevnu sobu i šuljam se u Gérardovu. On je 
skriven pod Everestom pohabanih pokrivača. Ispod njegova kreveta, pepeljara, budilica i fotografija Šveđanke na livadi, melakonična osmijeha. Kasno je i on lista knjigu i pije sok od grejpfruta s džinom. Sjedam na rub madraca i palim jednu od njegovih Craven cigareta od kojih mi se kašlje. “Ej, stari moj”, kažem mu s izrazom lica baptista, "vjerovao ili ne, mala je počinila samoubojstvo." Namrštim se. No on me pogleda sa zanimanjem, sjeda i iskreno se nasmije.

"Fantastično. Nadam se da je mrtva. Uzmi čašu da u to ime nazdravimo."

Oči mi se raskolače kao prvoga dana.

"Ali..."

“Ali baš ništa”, kaže mi. "To je ipak dobra vijest ovog tjedna, zar ne?"

Gleda me i hvata me palcem i srednjim prstom za bradu. Protrese mi lice kako bi s njega spale bore ozbiljnosti. Prasnem u iskren smijeh slična čaši šampanjca.

"Ne, nije mrtva”, kažem smijući se.

"Šteta", odgovara. "Glupa je, totalno glupa i ne mogu je vidjeti."

Srce mi se steže protiv moje volje.

"Ti je poznaješ, zar ne?"

"Ah, da, nekada..." suosjećajno izgovara i nabraja mi slučajeve kad su se sretali među prijateljima, trenutke sastajanja velikog društva na koje me nisu pozivali iz obzira prema meni. Ne prigovaram. Dok on odmotava klupko priče o prošlosti, ljušture koje mi prekrivaju oči raspadaju se i padaju. Odjednom otkrijem da priča o ljubavi, o ruci jednoga koja drži ruku drugoga, pred očima svih ostalih. Gérard me uči da vam život uvijek stavi pred nos ono što pokušavate sakriti iza rupičastog vjetrobrana. Žaljenje postaje sve dublje i dublje i buši jarke u mom sjećanju.

Tko su svi ti koji se na sva zvona zaklinju u naše prijateljstvo, a nisu odbili pružiti ruku i pozdraviti krivca za moj jad. S kakvom je samo lakoćom mala ukrala moje muškarce, a ja uključim svoju obitelj, zaklanjajući svim svojim zemaljskim oblikom njihov bezbrižan pogled, dok sam ja, dakle ja, mislila da ću lagano umrijeti od ljubavne izdaje. Slušajući svog rođaka kako se naslađuje uspomenama, obuzima me razočaranje, istinska trulež osjećaja. Uzalud se nalazim u prolaznosti, 
sram mi se penje uz čelo. Što je od to dvoje smješnije? Budimo iskreni, ja sam ta, povijest se tamo neće vratiti.

"Nemam što dodati, obična tuka”, završava Gérard i pruža mi svoju napola praznu čašu.

Zaustavlja na meni svoj pogled pun dobrote i procjenjuje da je o nekim stvarima bolje ne govoriti. Kad je stao, primijetim kako poravnava veo tajne na svijet koji je preokrutan. Gorčina me štipa sve jače.

Praznim čašu oponašajući ga. Ne želim previše komentirati noć te osobe koju svi poznaju. Sada svatko zna gdje je bio i što je radio onaj drugi u nekim jadnim trenucima moga postojanja. Vrijeme je od tada prohujalo, noseći sa sobom stvari takve kakve su bile i kakve ostaju za vječnost. Ali o tome ništa ne govorim želeći jednom čuvati svoje misli za sebe.

"Laka ti noć", kažem ustajući s kreveta. Odlazim spavati jer sutra radim od ranog jutra. Nadajmo se da će ponovo to učiniti. Ja nisam za to da svi budu sretni.

U prolazu stavljam prst na liniju i Nina Simone počne slavno jecati. Uvlačim se u svoju razbacanu posteljinu i odjednom me obuzme samoća. Bezobzirno plačem, sljubljena s ravnodušnim jastukom. Zvonjava telefona opet me iznenadi onako potpuno razočaranu. Pružam ruku i dižem slušalicu nabacujući masku na svoju fasadu.

"Sve je u redu", govori mi glas, "uspio sam se naći s Didierom. Obitelj će se o njoj pobrinuti. Ona ništa ne riskira."

"Ah dobro, umirio si nas. A ti si dobro?" odmah odgovaram, odlučna u tome da stvari stavim na svoje mjesto i pustim sadašnjost da sve popravi.

"A ne, nisam dobro", odgovara mi ponovo započevši svoju poznatu litaniju, ne mareći za suze koje su raskvasile moj jastuk.

Sve se vraća u normalu.

Kada je noćni razgovor završio, bili smo pomireni bez rasprave, što me je prije umirilo nego učinilo ponosnom. Oprezno sam prešla Crveno more i ukrotila njegove valove.

“Tko je to bio?" viknu Gérard kad je zveket telefona najavio kraj dosadne govorancije.

"Jean-Paul", vičem, dovoljno glasno da nadglasam pjevanje Nine Simone. 
"I?" dobaci Gérard sa svog kreveta.

"Ona je u bolnici i sve je u redu", dodajem.

"Ljubim te, stara moja, i dobro spavaj na svoja dva probušena uha", moj rođak izgovara kao preludij u san.

Kako, da, kako zamjeriti muškarcima koji čine našu svakodnevnicu?

Sada ponovno, noćima kada teško zaspim, mučena jednim ili drugim razlogom koji nas čine živima, proživljavam tu tragikomičnu epizodu. Zamišljam samoubojstvo, ali ovog puta dodajem smrt. Prstima svog duha, pritišćem dno njezina vrata i čekam da izdahne. Žalim što nije nestala te zimske večeri, kada sam ja njezinom krivicom bila potpuno zaboravljena, daleko od svoje djece i bez ijednog muškarca koji bi me podržao u nevolji.

Željela sam da je mrtva, to sam ponavljala samoj sebi, klonula u svom velikom stanu, sjedeći za stolom u kuhinji, na rubu sna, očiju izgubljenih u rublju koje se sušilo iznad sudopera. Ponekad mi se srdžba popne do ušiju i molim Gospodina da je podsjeti, ako je sada moguće, da se ponovo ubije ako ima imalo obzira.

Ja, koja nikada u životu nisam ni mrava zgazila, bez milosti želim istinsku smrt te mlade žene, slične mnogim drugima, koliko u načinu toliko u rezultatima. Nazovite to kako vam drago, za mene je to zločestoća. Ne izvlačim iz toga nepotreban ponos, ali sam svjesna njenog postojanja.

Muškarci se mogu vratiti. Ženama i onima iz moje obitelji rekla sam to što sam namjeravala reći. Prošle su godine na ovaj ili onaj način, a ja sam prihvatila sreću usprkos nepredvidivosti. Željela sam, međutim, precizirati, svima onima koje bi to moglo zanimati, da bih možda i ja mogla ubiti jednoga dana. To me čini radosnom i iskričavom poput šampanjca koji spava u hladnjaku i koji ćemo sada svi zajedno popiti, ako želite, u moje zdravlje.

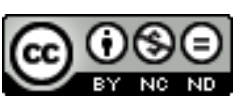

Creative Commons Attribution-NonCommercial-NoDerivatives 4.0 International License 